\title{
The Effect of Eutectic Mixture of Local Anesthesia Cream (EMLA) on Satisfaction, Pain, and Nausea/Vomiting of Patients Undergoing Gastro-intestinal Endoscopy-A Randomized Clinical Trial Comparing EMLA Cream and Gel, Lidocaine Gel and Spray, and Placebo
}

\author{
Jafar Nasiri ${ }^{1}$, Amin Ahmadi ${ }^{1} \&$ Forouzan Ganji $^{3}$ \\ ${ }^{1}$ Department of Internal Medicine, Shaharekord University of Medical Sciences, Shahrekord, Iran \\ ${ }^{3}$ Department of Community Medicine, Shahrekord University of Medical Sciences, Shahrekord, Iran \\ Correspondence: Jafar Nasiri, afar Nasiri Gastroenterologist, Assistant Professor, Department of Internal \\ Medicine, Shaharekord University of Medical Sciences, Shaharekord 88157-13471, Iran. Tel: 98-38-3222-3350. \\ Fax: 98-38-3224-3715. E-mail: jhnasiri@yahoo.com
}

Received: April 20, 2016 Accepted: May 4, 2016 Online Published: June 21, 2016

doi:10.5539/gjhs.v9n1p273 URL: http://dx.doi.org/10.5539/gjhs.v9n1p273

\begin{abstract}
Background and objectives: Esophagogastroduodenoscopy is a valuable diagnostic method for the treatment of various diseases that has found a wonderful application in recent years. Yet, controlling patients' pain and nausea is a fundamental factor to increase patient satisfaction, reduce patients' discomfort, and increase the patient's cooperation. Therefore, this study aimed to assess the efficacy of Eutectic Mixture of Local Anesthesia (EMLA) cream and gel, as a topical pharyngeal anesthetic on patients' pharyngeal pain, nausea/vomiting, and satisfaction, in comparison with lidocaine gel and spray and placebo.
\end{abstract}

Methods: This double-blind randomized clinical trial was conducted to assess patient satisfaction, nausea/vomiting, throat and pharyngeal pain during and after endoscopy by different methods of local anesthesia. Thus, 150 patients were randomly divided into 5 groups of 30 receiving placebo, lidocaine gel, lidocaine spray, EMLA gel and cream 5 to 10 minutes before endoscopy. Then patient satisfaction (measured by GHAA-9 questionnaire), pain or discomfort in the throat, and nausea/vomiting were evaluated half an hour after endoscopy.

Results: Patient satisfaction score was not statistically different between the test groups $(\mathrm{P}>0.05)$, but the throat pain and discomfort and nausea/vomiting during and after endoscopy was statistically different between groups $(\mathrm{P}<0.05)$ and the lowest nausea/vomiting was in the group using EMLA cream.

Conclusion: Different methods of throat anesthesia had no significant difference on patient satisfaction but EMLA cream and gel caused less nausea/vomiting than lidocaine gel or spray during and after endoscopy.

Keywords: Endoscopy; Patient Satisfaction; EMLA cream

\section{Introduction}

The use of esophagogastroduodenoscopy (EGD) has widely extended in diagnosis and treatment of various gastrointestinal (GI) pathologies recently; yet, like any other medical intervention, EGD is also not complication-free (Rondonotti et al., 2005). Patients undergoing EGD frequently complain of stress, pain, and nausea/vomiting, which significantly affect patient satisfaction, comfort, and cooperation; thus, various methods have been used to control pain during and after EGD (Thomson, Andrew, \& Jones, 2010), including intravenous (IV) and local anesthetic and analgesic drugs (Bell, 2002; Hickle, 2005).

Although IV sedation increases patient satisfaction (Trevisani et al., 2004), studies have indicated downward trend in its use due to fatal cardiopulmonary complications (Mulcahy et al., 2001). Therefore, topical pharyngeal anesthetics, like benzocaine and lidocaine, have been used to reduce patients' pain and decrease the required dose of IV sedation (Hedenbro, Ekelund, Jansson, \& Lindblom, 1992; Ristikankare, Hartikainen, Heikkinen, \& Julkunen, 2004). Although review studies have indicated the effectiveness of local anesthetics in increasing patients' tolerance and ease of endoscopy (Evans, Saberi, Kim, Elta, \& Schoenfeld, 2006), the precise efficacy 
and complication of each drug has to be evaluated (Thomson et al., 2010), as some have been recognized to induce some complications; for instance, life-threatening methemoglobinemia has be reported to be induced by local benzocaine and prilocaine (Guay, 2009; Kane, Hoehn, Behrenbeck, \& Mulvagh, 2007).

Eutectic Mixture of Local Anesthesia (EMLA) (containing $25 \mathrm{mg} / \mathrm{ml}$ of lidocaine and prilocaine) has recently been used as an effective topical anesthetic in various fields, including pediatric dermatologic local anesthesia (Chen \& Cunningham, 2001), oropharyngeal topical anesthesia in bronchoscopy (Sohmer, Bryson, Bencze, \& Scharf, 2003) and fiberoptic intubation (Larijani et al., 2000), and mucosal anesthesia (Barcohana, Duperon, \& Yashar, 2003; McMillan, Walshaw, \& Meechan, 2000). Dermatologic pediatric practices have established some side effects for EMLA including transient skin blanching, erythema, urticaria, allergic contact dermatitis, and purpura (Neri, Savoia, Guareschi, Medri, \& Patrizi, 2005). But EMLA has rarely been used to reduce patients' pain during and after EGD and the thorough details on its efficacy, benefits, and side effects in EGD have to be elucidated.

As long as EGD is associated with increased patients' anxiety (Jones et al., 2004), which is counter-related to patient satisfaction and cooperation (Mahajan, Johnson, \& Marshall, 1997), studies have recommended assessing the patients with a higher precision for evaluation of the efficacy of topical anesthetics.

Therefore, this study aimed to assess the efficacy of EMLA as a topical pharyngeal anesthetic on patients' pharyngeal pain, nausea/vomiting, and satisfaction.

\section{Materials and Methods}

\subsection{Patient Selection}

This double-blind randomized clinical trial (RCT) recruited patients who referred for upper gastro-intestinal endoscopy to the Endoscopy Center of Hajar hospital, Shahrekord city, Iran from May to September 2006. According to the calculated sample size, 150 patients were randomly recruited into the study.

\subsection{Study Design}

This clinical trial was double-blind and the physician performing the endoscopy, the person administering local anesthesia, and the patient were unaware of the type of the anesthetic used. The inclusion criteria comprised of patients' age over 12 years, patients undergoing non-emergency (outpatient) upper gastrointestinal endoscopy, patients with no previous experience of emergency or elective upper gastrointestinal endoscopy, and consent to undergo endoscopy and participate in the research. Exclusion criteria included patients with current acute gastrointestinal bleeding. After patient selection, a precise medical history was taken from all patients to assess the inclusion/exclusion criteria in patients and their demographic data, including age and gender was recorded and the selected patients were ultimately randomly assigned to five groups: Group A received $5 \mathrm{~g}$ EMLA cream (manufactured by Astrazenca company, UK), group B received EMLA gel, group C received lidocaine gel, group $\mathrm{D}$ received placebo gel (Plain lubricant gel as placebo gel), and group E received 3 puffs of $1 \%$ lidocaine spray on the posterior part of the tongue 5 minutes before endoscopy. Placebo gel was made of a carboxymethyl cellulose sodium salt and was similar in appearance and taste.

After upper gastrointestinal endoscopy, patient satisfaction was assessed by GHAA-9 questionnaire (Group Health Association of America), recommended by American Society of Gastrointestinal Endoscopy (Johanson et al., 2000) that has also been used in Iranian studies (Rahimian, 2008). The content validity of the questionnaire was confirmed by our specialists and test-retest was used to assess the reliability of the questionnaire and coefficient correlation was calculated at 0.7 for the questionnaire's reliability. The questionnaire has 15 questions with a score of 1-5 for each question, resulting in a total score of 15-75. Patients' pain and discomfort was assessed by a checklist based on Likert scale, in which 5=very good, $4=$ good, $3=$ average, $2=$ bad, and 1=very bad. Number of nausea/vomiting episodes of patients was also recorded.

\subsection{Statistical Methods}

The collected data was entered into SPSS software version 18.0. Continuous variables were reported as mean and standard deviation. Descriptive data was reported as frequency and percentage. As data was not normally distributed, non-parametric statistical tests were used for analysis of the difference in groups. Chi-square test was used to compare the patient satisfaction, pain and discomfort among groups and Mann-Whitney test was used to compare the mean episodes of nausea/vomiting among groups. P-values less than 0.05 have been considered as statistically significant.

\subsection{Ethical Considerations}

The protocol of the study was submitted in IRCT by the code IRCT201509136480N9 and was approved by 
Ethics Committee of Shahrekord University of Medical Sciences. The protocol and objectives of the study were explained to all patients and informed consent was obtained from all participants and those who were not willing to enter the study or continue the study at any phase were excluded from the study.

\section{Results}

The mean age of patients was $44.1 \pm 16.8$ and $76(50.7 \%)$ of participants were male and $74(49.3 \%)$ were female. The demographic characteristics of patients in each group is demonstrated in Table 1. There was no significant difference regarding age and gender among the five groups ( $\mathrm{P}=0.849$ and 0.924 , respectively).

Table 1. Demographic characteristics of patients in each group

\begin{tabular}{lll}
\hline & Mean and standard deviation of age & Male-female percentage \\
\hline Group A (EMLA cream) & $44.6 \pm 17.8$ & $16(53.3 \%)$ male and 14(46.7\%) female \\
Group B (EMLA gel) & $46.8 \pm 19.1$ & $16(53.3 \%)$ male and $14(46.7 \%)$ female \\
Group C (Lidocaine gel) & $44.2 \pm 15.6$ & $16(53.3 \%)$ male and $14(46.7 \%)$ female \\
Group D (Placebo) & $42.1 \pm 16.4$ & $15(50 \%)$ male and $15(50 \%)$ female \\
Group E (Lidocaine spray) & $42.8 \pm 15.7$ & $13(43.3 \%)$ male and 17(56.7\%) female \\
\hline
\end{tabular}

Patient satisfaction was marked as very good by $90 \%$ of patients in group A, $66.7 \%$ in group B, $56.8 \%$ in group $\mathrm{C}, 40 \%$ in group $\mathrm{D}$, and $60 \%$ in group $\mathrm{E}$, but chi-square test showed that patient satisfaction score was not statistically different in the test groups $(\mathrm{P}>0.05)$. The frequency of the scores that patients had given to GHAA-9 questionnaire is demonstrated as Table 2 .

Table 2. The frequency of the scores that patients had given to GHAA-9 questionnaire

\begin{tabular}{|c|c|c|c|c|c|c|c|c|c|c|}
\hline & \multicolumn{2}{|c|}{ Very good } & \multicolumn{2}{|c|}{ Good } & \multicolumn{2}{|c|}{ Average } & \multicolumn{2}{|c|}{ Bad } & \multicolumn{2}{|c|}{ Very bad } \\
\hline & No. & $\%$ & No. & $\%$ & No. & $\%$ & No. & $\%$ & No. & $\%$ \\
\hline Group A (EMLA cream) & 20 & 66.7 & 9 & 30 & 1 & 3.3 & 0 & 0 & 0 & 0 \\
\hline Group B (EMLA gel) & 27 & 90 & 2 & 6.7 & 0 & 0 & 1 & 3.3 & 0 & 0 \\
\hline Group C (Lidocaine gel) & 17 & 56.7 & 11 & 36.7 & 2 & 6.7 & 0 & 0 & 0 & 0 \\
\hline Group D (Placebo) & 12 & 40 & 12 & 40 & 3 & 10 & 0 & 0 & 3 & 10 \\
\hline Group E (Lidocaine spray) & 18 & 60 & 8 & 26.7 & 1 & 3.3 & 1 & 3.3 & 2 & 6.7 \\
\hline
\end{tabular}

Patients' throat pain and discomfort was marked as very good by $83.3 \%$ of patients in group A, $50 \%$ in group B, $50 \%$ in group C, $36.7 \%$ in group $\mathrm{D}$, and $46.7 \%$ in group $\mathrm{E}$. Throat pain and discomfort during and after endoscopy was statistically different between groups $(\mathrm{P}<0.05)$. The frequency of the scores that the patients had given to the amount of pain and discomfort is demonstrated as Table 3.

Table 3. The frequency of the scores that patients had given the amount of pain and discomfort

\begin{tabular}{|c|c|c|c|c|c|c|c|c|c|c|}
\hline & \multicolumn{2}{|c|}{ Very good } & \multicolumn{2}{|c|}{ Good } & \multicolumn{2}{|c|}{ Average } & \multicolumn{2}{|l|}{$\mathrm{Bad}$} & \multicolumn{2}{|c|}{ Very bad } \\
\hline & No. & $\%$ & No. & $\%$ & No. & $\%$ & No. & $\%$ & No. & $\%$ \\
\hline Group A (EMLA cream) & 25 & 83.3 & 4 & 13.3 & 0 & 0 & 1 & 3.3 & 0 & 0 \\
\hline Group B (EMLA gel) & 15 & 50 & 12 & 40 & 3 & 10 & 0 & 0 & 0 & 0 \\
\hline Group C (Lidocaine gel) & 15 & 50 & 11 & 36.7 & 4 & 13.3 & 0 & 0 & 0 & 0 \\
\hline Group D (Placebo) & 11 & 36.7 & 13 & 43.3 & 4 & 13.3 & 1 & 3.3 & 1 & 3.3 \\
\hline Group E (Lidocaine spray) & 14 & 46.7 & 12 & 40 & 2 & 6.7 & 1 & 3.3 & 1 & 3.3 \\
\hline
\end{tabular}

The mean and standard deviation of nausea/vomiting was $3.33 \pm 1.68$ in group A, $3.96 \pm 1.44$ in group B, 
4.36 \pm 2.23 in group C, $5.16 \pm 2.19$ in group $\mathrm{D}$, and $4.86 \pm 2.12$ in group $\mathrm{E}$. The difference between groups, analyzed by Mann-Whitney test, was significantly lower in EMLA cream than placebo, EMLA gel than placebo, EMLA cream than lidocaine spray $(\mathrm{P}<0.05)$ and was not significantly different between ELMA cream and gel $(\mathrm{P}>0.05)$.

\section{Discussion}

The results of the current RCT demonstrated that the throat and pharyngeal pain and discomfort and nausea/vomiting during and after endoscopy was significantly lower in EMLA cream group $(\mathrm{P}<0.05)$, which demonstrated the efficacy of EMLA cream and its superiority to lidocaine gel and spray.

The use of topical anesthetics in EGD has been recently proposed and different topical anesthetics have been investigated. Soma and colleagues have compared topical administration of $5 \mathrm{~mL}$ of $2 \%$ lidocaine hydrochloride with placebo and concluded lower anxiety and discomfort in swallowing the endoscope in the intervention group, especially in patients under 40 years (Soma et al., 2001). Leitch and colleagues have compared lidocaine spray to placebo and have suggested higher patient acceptability and tolerance in lidocaine group (Leitch, Wicks, El Beshir, Ali, \& Chaudhury, 1993). Hedenbro et al have also endorsed less throat discomfort and higher ease of examination by $80-120 \mathrm{mg}$ topical lidocaine, compared to placebo (Hedenbro et al., 1992). Various studies have also demonstrated severe life-threatening complications, like methemoglobinemia, for benzocaine and prilocaine (Guay, 2009; Kane et al., 2007).

Some studies have compared the efficacy of IV and topical anesthetics. Ristikankare et al have compared IV midazolam with lidocaine pharyngeal spray and placebo and have concluded that the topical pharyngeal anesthesia made endoscopy technically easier, but could not have a positive influence on patient tolerance, compared to IV sedation (Ristikankare et al., 2004).

EMLA cream has been widely used in different procedures (Barcohana et al., 2003; Chen \& Cunningham, 2001; Larijani et al., 2000; McMillan et al., 2000; Sohmer et al., 2003) and its efficacy and safety have been proven in different clinical trials (Friedman, Mafong, Friedman, \& Geronemus, 2001), but has rarely been used in reducing patients' pain during EGD. Fanurik et al have also established the efficacy of combination of distraction techniques with EMLA cream on children's distress during and after IV insertion (Fanurik, Koh, \& Schmitz, 2000). Randell and colleagues have also compared efficacy of lignocaine spray, gel, and swabs with EMLA cream in fibreoptic airway endoscopy and have determined EMLA cream as the least unpleasant agent and lignocaine spray and gel as better anesthetic agent in nasal mucosa, causing increase in arterial pressure (Randell, Yli-Hankala, Valli, \& Lindgren, 1992). As there are few studies assessing the efficacy of EMLA cream as local sedation in EGD, further studies have to be conducted to determine its precise efficacy and side effects.

In the present study, patient satisfaction score was not statistically different between EMLA, lidocaine, and placebo ( $\mathrm{P}>0.05)$, which might be resulted from inadequacy of the GHAA-9 questionnaire in assessing all factors affecting patient satisfaction (Yacavone et al., 2001), thus, we have added pain assessment to the questionnaire to be able to achieve more precise results, as far as pain is not included in GHAA-9 questionnaire. In addition, it might be due to the fact that patient satisfaction can be affected by various factors, such as personnel's manner and skill (Ko, Zhang, Telford, \& Enns, 2009), patients' information and preparedness prior to the intervention (Shepherd, Bowman, Hancock, Anglin, \& Hewett, 2000; van Vliet, Grypdonck, van Zuuren, Winnubst, \& Kruitwagen, 2004), and some demographic characteristics of patients like age, gender, gag reflex, and baseline anxiety (Campo et al., 1999; Trevisani et al., 2004), however, we tried to match or exclude some important factors established to have controversial effects on patient satisfaction in the current study like previous experience of EGD (Drossman et al., 1996; Rabeneck, Wristers, Souchek, \& Ambriz, 2003). Although some other questionnaires have been proposed (Peña, Mardini, \& Nickl, 2005), GHAA-9 questionnaire seems to be the most valid and reliable assessment tool for patient satisfaction (del Río, Baudet, Fernandez, Morales, \& del Rosario Socas, 2007). It might also be due to the nature of EGD, as swallowing the endoscope reduces patients' tolerance and causes discomfort for patients (Walmsley \& Montgomery, 1998).

Due to the limited number of clinical trials assessing topical anesthetics in EGD, especially EMLA cream, it is strongly suggested that further studies investigate the precise efficacy and side effects of EMLA cream in EGD.

Beside the strengths of the current study, including the randomized nature of the trial, controlling the confounding factors, assessment of patients' throat pain and discomfort and nausea/vomiting beside GHAA-9 questionnaire, which has scarcely been evaluated in studies, our study was also not free from limitations. Due to the fact that various factors affect patient satisfaction and GHAA-9 questionnaire might be insufficient, it would be better if patient anxiety was simultaneously evaluated by a valid questionnaire like State-Trait Anxiety Index, as anxiety is closely related to patient satisfaction. 


\section{Conclusion}

Although some studies have concluded that topical anesthetics should be used as a premedication in inducing anesthesia in EGD and is not sufficient (Randell et al., 1992), review studies have indicated their efficacy (Thomson et al., 2010), similarly, the current study could prove the efficacy of EMLA cream, as a topical pharyngeal anesthetic, on reducing patients' pain and discomfort and nausea/vomiting during and after EGD, although EMLA was not significantly different from lidocaine regarding patient satisfaction.

\section{Financial Support and Sponsorship}

Nil.

\section{Competing Interests Statement}

The authors declare that there is no conflict of interests regarding the publication of this paper.

\section{References}

Barcohana, N., Duperon, D. F., \& Yashar, M. (2003). The relationship of application time to EMLA efficacy. Journal of dentistry for children, 70(1), 51-54.

Bell, G. (2002). Premedication, preparation, and surveillance. Endoscopy, 34(1), 2-12. http://dx.doi.org/10.1055/s-2002-19389

Campo, R., Brullet, E., Montserrat, A., Calvet, X., Moix, J., Rué, M., . . Bordas, J. M. (1999). Identification of factors that influence tolerance of upper gastrointestinal endoscopy. European journal of gastroenterology \& hepatology, 11(2), 201-204. http://dx.doi.org/10.1097/00042737-199902000-00023

Chen, B. K., \& Cunningham, B. B. (2001). Topical anesthetics in children: Agents and techniques that equally comfort patients, parents, and clinicians. Current opinion in pediatrics, 13(4), 324-330. http://dx.doi.org/10.1097/00008480-200108000-00007

del Río, A. S., Baudet, J. S., Fernandez, O. A., Morales, I., \& del Rosario Socas, M. (2007). Evaluation of patient satisfaction in gastrointestinal endoscopy. European journal of gastroenterology \& hepatology, 19(10), 896-900. http://dx.doi.org/10.1097/MEG.0b013e3281532bae

Drossman, D. A., Brandt, L. J., Sears, C., Li, Z., Nat, J., \& Bozymski, E. M. (1996). A preliminary study of patients' concerns related to GI endoscopy. The American journal of gastroenterology, 91(2), 287-291.

Evans, L. T., Saberi, S., Kim, H. M., Elta, G. H., \& Schoenfeld, P. (2006). Pharyngeal anesthesia during sedated EGDs: is "the spray" beneficial? A meta-analysis and systematic review. Gastrointestinal endoscopy, 63(6), 761-766. http://dx.doi.org/10.1016/j.gie.2005.11.059

Fanurik, D., Koh, J. L., \& Schmitz, M. L. (2000). Distraction techniques combined with EMLA: Effects on IV insertion pain and distress in children. Children's Health Care, 29(2), 87-101. http://dx.doi.org/10.1207/S15326888CHC2902_2

Friedman, P. M., Mafong, E. A., Friedman, E. S., \& Geronemus, R. G. (2001). Topical anesthetics update: $\begin{array}{llll}\text { EMLA and beyond. Dermatologic } & \text { 1019-1026. }\end{array}$ http://dx.doi.org/10.1097/00042728-200112000-00006

Guay, J. (2009). Methemoglobinemia related to local anesthetics: A summary of 242 episodes. Anesthesia \& Analgesia, 108(3), 837-845. http://dx.doi.org/10.1213/ane.0b013e318187c4b1

Hedenbro, J., Ekelund, M., Jansson, O., \& Lindblom, A. (1992). A randomized, double-blind, placebo-controlled study to evaluate topical anaesthesia of the pharynx in upper gastrointestinal endoscopy. Endoscopy, 24(6), 585-587. http://dx.doi.org/10.1055/s-2007-1010550

Hickle, R. S. (2005). Systems and methods for providing gastrointestinal pain management: Google Patents.

Johanson, J. F. S. C., Deas, T. M., et al. (2000). Quality and outcomes assessment in gastrointestinal endoscopy. Gastrointest Endosc, 52, 827-830. http://dx.doi.org/10.1016/S0016-5107(00)70218-5

Jones, M. P., Ebert, C. C., Sloan, T., Spanier, J., Bansal, A., Howden, C. W., \& Vanagunas, A. D. (2004). Patient anxiety and elective gastrointestinal endoscopy. Journal of clinical gastroenterology, 38(1), 35-40. http://dx.doi.org/10.1097/00004836-200401000-00009

Kane, G. C., Hoehn, S. M., Behrenbeck, T. R., \& Mulvagh, S. L. (2007). Benzocaine-induced methemoglobinemia based on the Mayo Clinic experience from 28478 transesophageal echocardiograms: incidence, outcomes, and predisposing factors. Archives of internal medicine, 167(18), 1977-1982. 
http://dx.doi.org/10.1001/archinte.167.18.1977

Ko, H. H., Zhang, H., Telford, J. J., \& Enns, R. (2009). Factors influencing patient satisfaction when undergoing $\begin{array}{llll}\text { endoscopic procedures. } & \text { Gastrointestinal }\end{array}$ http://dx.doi.org/10.1016/j.gie.2008.06.024

Larijani, G. E., Cypel, D., Gratz, I., Mroz, L., Mandel, R., Afshar, M., \& Goldberg, M. E. (2000). The efficacy and safety of EMLA ${ }^{\circledR}$ Cream for awake fiberoptic endotracheal intubation. Anesthesia \& Analgesia, 91(4), 1024-1026. http://dx.doi.org/10.1097/00000539-200010000-00048

Leitch, D. G., Wicks, J., El Beshir, O. A., Ali, S. A., \& Chaudhury, B. K. (1993). Topical anesthesia with $50 \mathrm{mg}$ of lidocaine spray facilitates upper gastrointestinal endoscopy. Gastrointestinal endoscopy, 39(3), 384-387. http://dx.doi.org/10.1016/S0016-5107(93)70110-8

Mahajan, R. J., Johnson, J. C., \& Marshall, J. B. (1997). Predictors of patient cooperation during gastrointestinal $\begin{array}{lllll}\text { endoscopy. Journal of clinical } & \text { gastroenterology, 220-223. }\end{array}$ http://dx.doi.org/10.1097/00004836-199706000-00007

McMillan, A., Walshaw, D., \& Meechan, J. (2000). The efficacy of Emla ${ }^{\circledR}$ and 5\% lignocaine gel for anaesthesia of human gingival mucosa. British Journal of Oral and Maxillofacial Surgery, 38(1), 58-61. http://dx.doi.org/10.1054/bjom.1999.0143

Mulcahy, H., Hennessy, E., Connor, P., Rhodes, B., Patchett, S., Farthing, M., \& Fairclough, P. (2001). Changing patterns of sedation use for routine out - patient diagnostic gastroscopy between 1989 and 1998. Alimentary pharmacology \& therapeutics, 15(2), 217-220. http://dx.doi.org/10.1046/j.1365-2036.2001.00912.x

Neri, I., Savoia, F., Guareschi, E., Medri, M., \& Patrizi, A. (2005). Purpura after application of EMLA cream in two children. Pediatric dermatology, 22(6), 566-568. http://dx.doi.org/10.1111/j.1525-1470.2005.00142.x

Pe-a, L. R., Mardini, H. E., \& Nickl, N. J. (2005). Development of an instrument to assess and predict satisfaction and poor tolerance among patients undergoing endoscopic procedures. Digestive diseases and sciences, 50(10), 1860-1871. http://dx.doi.org/10.1007/s10620-005-2952-7

Rabeneck, L., Wristers, K., Souchek, J., \& Ambriz, E. (2003). Impact of upper endoscopy on satisfaction in patients with previously uninvestigated dyspepsia. Gastrointestinal endoscopy, 57(3), 295-299. http://dx.doi.org/10.1067/mge.2003.122

Rahimian G, N., J, Pourshams, A, Ganji, F. (2008). Comparison of Three Premedication Regimens for Pain Relief and Patient's Satisfaction During Routine Colonoscopy. GOVARESH, 12(4), 249-252.

Randell, T., Yli-Hankala, A., Valli, H., \& Lindgren, L. (1992). Topical anaesthesia of the nasal mucosa for fibreoptic airway endoscopy. British journal of anaesthesia, 68(2), 164-167. http://dx.doi.org/10.1093/bja/68.2.164

Ristikankare, M., Hartikainen, J., Heikkinen, M., \& Julkunen, R. (2004). Is routine sedation or topical pharyngeal anesthesia beneficial during upper endoscopy? Gastrointestinal endoscopy, 60(5), 686-694. http://dx.doi.org/10.1016/S0016-5107(04)02048-6

Rondonotti, E., Herrerias, J. M., Pennazio, M., Caunedo, A., Mascarenhas-Saraiva, M., \& de Franchis, R. (2005). Complications, limitations, and failures of capsule endoscopy: a review of 733 cases. Gastrointestinal endoscopy, 62(5), 712-716. http://dx.doi.org/10.1016/j.gie.2005.05.002

Shepherd, H., Bowman, D., Hancock, B., Anglin, J., \& Hewett, D. (2000). Postal consent for upper gastrointestinal endoscopy. Gut, 46(1), 37-39. http://dx.doi.org/10.1136/gut.46.1.37

Sohmer, B., Bryson, G. L., Bencze, S., \& Scharf, M. M. (2003). EMLA cream is an effective topical anesthetic for bronchoscopy. Canadian respiratory journal: journal of the Canadian Thoracic Society, 11(8), 587-588. http://dx.doi.org/10.1155/2004/780482

Soma, Y., Saito, H., Kishibe, T., Takahashi, T., Tanaka, H., \& Munakata, A. (2001). Evaluation of topical pharyngeal anesthesia for upper endoscopy including factors associated with patient tolerance. Gastrointestinal endoscopy, 53(1), 14-18. http://dx.doi.org/10.1067/mge.2001.111773

Thomson, A., Andrew, G., \& Jones, D. B. (2010). Optimal sedation for gastrointestinal endoscopy: review and recommendations. Journal of gastroenterology and hepatology, 25(3), 469-478. http://dx.doi.org/10.1111/j.1440-1746.2009.06174.x

Trevisani, L., Sartori, S., Gaudenzi, P., Gilli, G., Matarese, G., Gullini, S., \& Abbasciano, V. (2004). Upper 
gastrointestinal endoscopy: Are preparatory interventions or conscious sedation effective? A randomized trial. World Journal of Gastroenterology, 10(22), 3313-3317. http://dx.doi.org/10.3748/wjg.v10.i22.3313

van Vliet, M. J., Grypdonck, M., van Zuuren, F. J., Winnubst, J., \& Kruitwagen, C. (2004). Preparing patients for gastrointestinal endoscopy: The influence of information in medical situations. Patient education and counseling, 52(1), 23-30. http://dx.doi.org/10.1016/S0738-3991(02)00245-8

Walmsley, R., \& Montgomery, S. (1998). Factors affecting patient tolerance of upper gastrointestinal endoscopy. Journal of clinical gastroenterology, 26(4), 253-255. http://dx.doi.org/10.1097/00004836-199806000-00006

Yacavone, R. F., Locke, G. R., Gostout, C. J., Rockwood, T. H., Thieling, S., \& Zinsmeister, A. R. (2001). Factors influencing patient satisfaction with GI endoscopy. Gastrointestinal endoscopy, 53(7), 703-710. http://dx.doi.org/10.1067/mge.2001.115337

\section{Copyrights}

Copyright for this article is retained by the author(s), with first publication rights granted to the journal.

This is an open-access article distributed under the terms and conditions of the Creative Commons Attribution license (http://creativecommons.org/licenses/by/3.0/). 